\title{
«QUE DE AMBOS OFICIOS ERA DIOS SERVIDO». EL ORIGEN DE LA DUALIDAD LITÚRGICA TOLEDANA EN LA HISTORIOGRAFÍA RENACENTISTA
}

\author{
POR
}

\author{
JuAn Pablo Rubio SAdia, OSB \\ Abadía de la Santa Cruz del Valle de los Caídos
}

\section{RESUMEN}

La abolición de la liturgia hispánica sancionada por el rey Alfonso VI a finales del siglo XI tuvo una aplicación peculiar en la ciudad de Toledo, que dio lugar a una excepcional dualidad ritual. En este artículo se analizan los argumentos aducidos por cinco destacados intelectuales toledanos del Renacimiento para justificar la pervivencia del antiguo rito junto al romano, considerando su lectura de la tradición historiográfica, el valor de sus interpretaciones, así como la intencionalidad de sus relatos. El estudio nos permite conocer hasta qué punto existe un propósito de legitimación del origen de aquella tolerancia precisamente cuando el rito acababa de ser restaurado por el cardenal Cisneros y gozaba de una gran veneración en los ambientes eclesiales y humanistas del Toledo del siglo XVI.

PAlABRAS CLAVE: Toledo, Alfonso VI, Dualidad litúrgica, Rito hispano (mozárabe, toledano, gótico), Rito romano (galicano, gregoriano, francés), Historiografía renacentista.

\begin{abstract}
The abolition of the Hispanic rite sanctioned by King Alfonso VI at the end of 11 th century had a special application in Toledo, which gave rise to an exceptional liturgical duality. In this article the arguments put forward by five notable Renaissance Toledan intellectuals are analysed in order to justify the continuation of the Old Spanish rite together with the Roman rite, with regard to their reading of the historiographic tradition, the value of their interpretations and the narrative purpose. This study gives us an understanding of to what extent there is a specific intention of legitimizing the origin of this acceptance when the
\end{abstract}


rite had just been restored by Cardinal Cisneros and enjoyed a great veneration in the humanist and ecclesiastical groups within Toledo throughout 16th century.

KEY WORDS: Toledo, Alfonso VI, liturgical duality, Hispanic rite (Mozarabic, Toledan, Gothic), Roman rite (Gallican, Gregorian, French), Renaissance historiography.

Recibido/Received 04-06-2006

Aceptado/Accepted 20-07-2006

\section{INTRODUCCIÓN}

La decisión de sustituir la liturgia hispánica por la romana en el reino de Castilla y León se produjo cinco años antes de la reconquista de Toledo, sin que afectara a la comunidad cristiana que allí vivía bajo dominio musulmán. Con el cambio de poder el año 1085 llegó la hora de aplicar en la ciudad imperial la resolución del rey Alfonso VI, planteándose un conflicto entre los eclesiásticos cluniacenses, responsables de la restauración diocesana y la implantación del romanum officium, y la comunidad mozárabe local, que había sobrevivido en medio de la cultura árabe y estaba fuertemente aferrada a su liturgia ancestral. En aquella situación las prioridades políticas prevalecieron sobre los criterios eclesiásticos, y la urgencia por retener y atraer pobladores que asegurasen la posesión de la ciudad hizo que el monarca concediera un privilegio especial a los mozárabes, garantizándoles la libre celebración de su oficio litúrgico. Esta política de tolerancia impuesta por Alfonso, silenciada en el fuero de 1101, está en el origen de la dualidad ritual. Más de cuatro siglos después, el arzobispo don Francisco Jiménez de Cisneros (1495-1517) impulsaba la tarea de restauración y reforma del rito hispano, que se hallaba en un estado de completa postración. A partir de entonces, y a lo largo del siglo XVI, historiadores y humanistas toledanos, en un contexto de veneración hacia aquella liturgia «joya de los Padres visigodos», ensayan una reconstrucción de su historia.

En estas páginas vamos a analizar los textos referentes al origen de la dualidad litúrgica toledana de cinco autores vinculados a la ciudad imperial (Blas Ortiz, Pedro de Alcocer, Alvar Gómez de Castro, Juan de Mariana y Francisco de Pisa), considerando las razones que aducen para dar respuesta a una cuestión clave: ¿por qué se autorizó en la urbs regia la celebración del oficio de los mozárabes en contra de la normativa general del reino? Este estudio nos va a permitir no sólo precisar las fuentes cronísticas que manejaron a la hora de exponer el cambio de rito, sino también valorar de qué modo y con qué finalidad se utilizaron e interpretaron los materiales épicos y legendarios. 


\section{FUENTES NARRATIVAS Y CLAVES HERMENÉUTICAS}

Antes de abordar lo específico de nuestro estudio, es interesante presentar algunas claves para llevar a cabo una adecuada interpretación de los textos. Por lo que se refiere a las fuentes, es evidente que la narración de las vicisitudes que rodearon la implantación del rito romano en Toledo depende fundamentalmente de la obra De rebus Hispanie $(R H)$ del arzobispo don Rodrigo Jiménez de Rada (1170-1247) ${ }^{1}$. Como hemos señalado ya en otro trabajo ${ }^{2}$, la crónica del Toledano refleja a su vez un conocimiento tanto de la crónica del obispo don Pelayo de Oviedo $^{3}$ como de la Najerense ${ }^{4}$, si bien suele imprimir un estilo personal a los materiales que compila 5 . Tampoco podemos descartar que ese material cronístico fuera conocido indirectamente a través de otras fuentes legendarias o juglarescas hoy perdidas ${ }^{6}$. En este sentido apunta la hipótesis de Bernard F. Reilly, según la cual don Rodrigo dispuso de «dos fuentes escritas mayores»: una vita o gesta del arzobispo don Bernardo de Sauvetat y un Cantar de Alfonso VI ${ }^{7}$.

Sin entrar en mayores detalles, lo cierto es que $R H$ supone un giro muy significativo e influyente en la historiografía posterior acerca de la crisis ritual ${ }^{8}$. Merece la pena recordar que en esta obra la ciudad de Toledo figura como gran escenario del relato épico del certamen entre caballeros y la ordalía del fuego celebrados para determinar qué rito debía prevalecer en la Iglesia castellanoleonesa, relato que había aparecido por vez primera -según nos consta- en la

\footnotetext{
${ }^{1}$ Rodrigo JimÉnez DE RADA, Historia de rebus Hispanie sive Historia Gothica, cura et studio Juan Fernández Valverde, (Corpus Christianorum. Continuatio Mediavalis 72), Turnhout 1987, lib. VI, caps. XXIV-XXV, pp. 205-209.

2 Juan Pablo RUBIO SADIA, «El cambio de rito en Castilla: su iter historiográfico en los siglos XII y XIII», Hispania Sacra 58 (2006) 28-34.

${ }^{3}$ Benito SÁnchez Alonso (ed.), Crónica del obispo don Pelayo, Madrid 1924, p. 80.

${ }^{4}$ Chronica Hispana saculi XII. Pars II. Chronica Naierensis, cura et studio Juan Antonio EsTÉVEZ SolA, (Corpus Christianorum. Continuatio Mediavalis 71A), Turnhout 1995, lib. III, cap. XVIII, p. 177.

5 Benito SÁnchez Alonso, Historia de la historiografía española I, Madrid 1947, p. 207.

${ }^{6}$ FERnÁndeZ VALVERdE, pp. XXXV-XXXVI.

${ }^{7}$ Según esta hipótesis, de la vita de don Bernardo Jiménez de Rada habría tomado lo referente a la introducción de la liturgia romana en Castilla y León, y del Cantar de Alfonso VI derivaría el famoso relato del duelo y del fuego; Bernard F. REILLY, «El reinado de Alfonso VI de León y Castilla, de Rodrigo Jiménez de Rada, en el De rebus Hispania; metodología histórica en el siglo XIII», Toletum, $2^{\text {a }}$ época, 23 (1989 145-147.

${ }^{8}$ Sobre su influencia, recordemos que su relato pasó en forma de traducción libre a la Primera crónica general de España, compuesta entre 1270 y 1280; Ramón MENÉNDEZ PIDAL (ed.), Madrid 1955, t. II, pp. 542-543. La obra de Alfonso el Sabio nutriría por mucho tiempo la producción historiográfica como ha indicado SÁnchez Alonso, Historia de la historiografía I, p. 208. Su narración del cambio de rito, sin embargo, no aparece en la Crónica de 1344 o Segunda crónica general al tratar sobre el reinado de Alfonso VI, a quien se refiere repetidamente como «el que ganó a Toledo a los moros»; Diego Catalán y Ma . Soledad de AndrÉs (eds.), Madrid 1971, p. 207.
} 
Crónica Najerense y cuyo contexto original era la ciudad de Burgos y el año 10779. La composición de $R H$, en efecto, mezcla sucesos, traslada acontecimientos de lugar y de fecha y exagera ciertos aspectos en función de un objetivo concreto: defender la causa de Toledo, es decir, su primacía eclesiástica en un momento de insumisión por parte de los arzobispos de Tarragona, Braga y Compostela. El tratamiento de este tema sugiere que lo que realmente le importa a don Rodrigo es que la sede primada que él gobierna quede vinculada a un acontecimiento de relevancia «nacional» 10 .

En el siglo XVI los intelectuales de la ciudad imperial conocen a fondo la obra de Jiménez de Rada y, de hecho, la utilizan ampliamente. Al mismo tiempo, comparten una serie de rasgos, aunque con matices de intensidad, que debemos tener en cuenta en nuestro análisis. Señalemos tan sólo los más significativos. En primer lugar, Toledo es considerada «la mas noble de las cibdades de España» (Alcocer), «nobilísima ciudad, columna que era de España» (Mariana), «nombradíssima en todo el orbe» (Ortiz). Esta visión ideal de Toledo se proyecta, de alguna forma, hacia su rey reconquistador Alfonso VI (10651109), protagonista de la pervivencia del antiguo rito hispánico, tenido como un «magnifico y excelente rey» (Alcocer) y un príncipe «christiano y prudente» (Pisa). Asimismo, hacia la primitiva comunidad mozárabe toledana existe un sentir muy favorable, «porque como buenos [cristianos] auian perseuerado siempre, ellos y sus predecessores en nuestra sancta fee católica» (Alcocer), lo cual se extiende a «las ceremonias tan santas de los antiguos cristianos» (Gómez de Castro), usadas en España «desde muy antiguos tiempos por autoridad de los santos Isidoro, Ildefonso y Juliano» (Mariana). No resultan extraños, por consiguiente, los elogios dirigidos al cardenal Cisneros, «varón tan fervoroso y devoto venerador de la religión, y estudiosíssimo observador de las antiguas ceremonias» (Ortiz), en especial por su obra restauradora ${ }^{11}$, «empresa merecedora de grandes elogios» $\mathrm{y}$ «asunto de tanta loa y magnificencia» (Gómez de Castro). Notemos a este respecto que, en los ambientes humanistas y reformistas, el rito hispano se halla muy lejos de ser aquella superstitio toletana que considerara el papa Gregorio VII a finales del siglo XI ${ }^{12}$. Ahora es contemplado con

\footnotetext{
${ }^{9}$ Una síntesis de estos hechos puede verse en mi estudio Juan Pablo RUBIO SADIA, Las órdenes religiosas y la introducción del rito romano en la Iglesia de Toledo, Toledo 2004, pp. 51-61.

10 RuBio SADIA, «El cambio de rito», pp. 31-32.

${ }^{11}$ Aún reconociendo el gran valor de la obra cisneriana, no está de más recordar que «el rito mozárabe, para salvarse en el siglo XVI, paga el tributo de uniformarse prácticamente con el rito romano en sus modos de celebrar y expresar. Quien no entendía el latín apenas podría diferenciar la Misa hispana de una romana local»; Juan-Miguel FerRER GRENESCHE (dir.), Curso de liturgia hispano-mozárabe, Toledo 1995 , p. 32.

12 Una buena exposición del trasfondo de descalificación doctrinal del rito hispano por parte de los pontífices romanos puede verse en José ORLANDIS, «Toletanæ illusionis superstitio», Scripta Theologica 18 (1986) 197-213. Para el pensamiento propio de Gregorio VII véase José María Soto RÁBAnOs,
}

Hispania Sacra, LIX

119, enero-junio 2007, 141-162, ISSN: 0018-215-X 
nuevos ojos como «un legado cultural y religioso heredado de los mayores, que es preciso recuperar» ${ }^{13}$.

Partiendo de estas coordenadas, es importante subrayar asimismo que, si bien la obra del Toledano proporcionaba a nuestros autores una amplia base historiográfica, no explicaba, sin embargo, los motivos que impulsaron al rey Alfonso a permitir la liturgia de la minoría mozárabe toledana junto a la Lex romana. Don Rodrigo, en efecto, no se vio en la necesidad de justificar el origen de aquella excepcional tolerancia, aunque la conocía perfectamente, al igual que conocía la pervivencia del rito hispano en seis parroquias durante los siglos de la dominación musulmana ${ }^{14}$. Ahora, en el Toledo del Renacimiento es, sobre todo, el culto apasionado por los aspectos gloriosos de la antigüedad nacional lo que impulsa a colmar este vacío, empleando para ello diferentes procedimientos narrativos. Parece menos probable, aunque podría haber influido en algunas expresiones de Pedro de Alcocer y Francisco de Pisa, el deseo de defender a los mozárabes de Toledo, objeto de ciertas sospechas y prejuicios, especialmente en la segunda mitad del siglo XVI ${ }^{15}$. Esta actitud de animosidad, señalada por Richard Hitchcock, no se ve suficientemente reflejada en nuestros textos a la hora de referirse al rito autóctono; es decir, no aparece como una mentalidad que se pretenda rebatir. Prueba de ello es la completa ausencia -como vamos a ver- del tono polémico o apologético que cabría esperar, por ejemplo, en el caso de Pisa, un capellán mozárabe.

Por último, digamos una palabra acerca de la tipología de los relatos objeto de nuestro estudio y del género historiográfico en el cual se insertan. En cuanto

\footnotetext{
«Introducción del rito romano en los reinos de España. Argumentos del papa Gregorio VII», Studi Gregoriani per la Storia della «Libertas Ecclesia» XIV (1991) 161-174.

${ }^{13}$ Ramón GonZÁlvez RuIZ «isneros y la reforma del rito hispano-mozárabe», Anales toledanos 40 (2004) 200.

14 «Postquam uero urbs regia fuit non irruptione sed federe ab Arabibus occupata, quod tamen fedus Sarraceni postea irruperunt, clerus et Christiani eiecti cum aliis, qui in Hispaniis seruituti barbarice mancipati elegerunt degere sub tributo, permissi sunt uti lege et ecclesiasticis institutis et habere pontifices et euangelicos sacerdotes, apud quos uiguit officium Isidori et Leandri et uiguet hodie in VI parrochiis Toletanis»; JIMÉNEZ DE RADA, lib. IIII, cap. III, p. 118. Sobre los templos propios de los mozárabes en la etapa de la restauración puede verse Juan Francisco Rivera ReCIO, La Iglesia de Toledo en el siglo XII (1086-1208), vol. I, Roma 1966, pp. 87-90.

${ }^{15}$ Según opinión del profesor Hitchcock, la situación de los mozárabes de Toledo fue empeorando progresivamente a lo largo del siglo XVI. Del optimismo que siguió a la restauración cisneriana se llegó a una "posición crítica», motivada por «una envidia y una desconfianza» en un ambiente muy sensible a la pureza de sangre; Richard Hттснсоск, «La imagen literaria de los mozárabes en el Siglo de Oro», Actas del IX Congreso de la Asociación Internacional de Hispanistas, (Berlín 18-23 agosto 1986), publicadas por Sebastian NeUMEISTER, Frankfurt am Main 1989, vol. I, pp. 487-494. Sin entrar en ciertos puntos discutibles de este trabajo, hay que afirmar que el sentimiento al que se refiere no adquirió un carácter mayoritario entre la población de la ciudad. En todo caso, su origen no debió estar en los usos litúrgicos propios de los mozárabes, sino en su condición de grupo social privilegiado.
} 
a la primera, distinguimos dos formas de narración: la de una historia breve del rito hispánico, dentro de la cual se incluye la introducción de la liturgia romana en Toledo tras su conquista (Ortiz y Gómez de Castro), y la de un relato del cambio de rito configurado como un capítulo independiente (Pedro de Alcocer, Juan de Mariana y Francisco de Pisa). Respecto al género de las obras, existe una mayor diversidad. Encontramos una gran historia de carácter nacional (Mariana), dos descripciones o historias locales sobre Toledo (Alcocer y Pisa), una guía de la catedral primada (Ortiz) y, finalmente, una biografía del cardenal Cisneros (Gómez de Castro).

\section{LA INTERPRETACIÓN LEGENDARIA A PARTIR DEL MILAGRO DEL FUEGO}

\section{Blas Ortiz (1485-1552)}

Nacido en Villarrobledo, pero vinculado a Toledo desde 1524 gracias a la obtención de una canonjía doctoral, Blas Ortiz destaca entre los intelectuales toledanos de su época por ser autor de la primera guía o descripción que conocemos de la catedral primada, a la que tituló Summi Templi Toletani Descriptio ${ }^{16}$, compuesta para satisfacer el deseo del joven príncipe Felipe de conocerla con mayor profundidad tras una visita realizada en diciembre de $1546^{17}$. Más que un historiador o un humanista propiamente dicho, el doctor Ortiz era un experto en cánones ${ }^{18}$. No obstante, su erudita y prolija Descripción constituye nuestro punto de partida, ya que incluye un esbozo de la historia de Toledo y del rito hispánico, que habrá de influir, por otra parte, en otros historiadores toledanos como Pedro de Alcocer o Francisco de Pisa ${ }^{19}$.

Nuestro interés está centrado en el capítulo 42 (De la Capilla de los Muzárabes, y Origen de sus Sacrificios) dentro de la sección descriptiva de la obra

16 Contamos con una reciente y excelente edición bilingüe de esta obra: La Catedral de Toledo 1549, según el doctor Blas Ortiz. Descripcion Graphica y Elegantissima de la S. Iglesia de Toledo, Toledo 1999 (citaremos como ORTIZ, Descripción). En adelante, seguiremos la traducción española de dicha edición que corresponde al Manuscrito 210 de la Biblioteca Pública del Estado (Toledo).

17 «El objetivo que perseguía Blas Ortiz con su Descripción era el de ofrecer al príncipe la posibilidad de satisfacer su curiosidad sobre la catedral y su edificio, recrearla ante sus ojos para que como por un cancel pudiera disfrutar de su historia y su arquitectura ya que en su última visita no había tenido el tiempo necesario para detenerse en sus innumerables riquezas»; Felipe PEREDA, «Leer en la Catedral: La experiencia de la arquitectura en 1549», en ORTIZ, Descripción, p. 96.

18 Resulta rotunda, a este respecto, la afirmación de Gonzálvez: «Blas Ortiz era un hombre del Derecho y no tiene otro horizonte que el Derecho»; Ramón GonZÁlvEZ RuIz, «Blas Ortiz y su mundo», en ORTIZ, Descripción, p. 32.

19 Para estos autores los términos «historia» y «descripción» eran prácticamente sinónimos, por influjo de la tradición clásica; Ibidem, pp. 12-13.

Hispania Sacra, LIX

119, enero-junio 2007, 141-162, ISSN: 0018-215-X 
(caps. 5-65). Según Ramón Gonzálvez, este capítulo dedicado a la capilla mozárabe del Corpus Christi, que por entonces ya funcionaba con regularidad, es uno de los mejor elaborados de todo el libro ${ }^{20}$. Aquel espacio celebrativo, todo un símbolo de la reforma cisneriana, constituye la ocasión para que Ortiz exponga al príncipe Felipe cuáles fueron los orígenes y la trayectoria histórica de «los oficios que se llaman muzárabes» que continúan celebrándose en ella ${ }^{21}$. Por consiguiente, se trazan aquí las diferentes etapas del rito, desde sus orígenes hasta su decadencia y restauración, deteniéndose en la crisis surgida a raíz de la implantación del rito romano. Sirviéndose de un estilo muy elaborado y ampuloso, notablemente amplificado con los recursos propios de la literatura épica, Ortiz recrea el relato del duelo entre caballeros y de la hoguera de acuerdo con los tópicos de $R H$. Según todos los indicios, parece querer captar la atención de su lector describiéndole una escena fabulosa:

Elegidos pues dos soldados para pelear, uno por el rito toledano y otro por el francés, se señaló el día del certamen, se dispuso el lugar, fue mucha la gente que concurrió a verle, e igual el miedo, temiendo cada uno por su parte, y haciendo promesas a los santos por su soldado. En fin llegando el día de la batalla, llenándose el lugar del espectáculo con la frequente turba de los mortales, se obstentaron armados en medio del circo los combatientes. Y abiéndose hecho señal de embestir, bolbieron las armas para herirse con gran fortaleza y valor. Encendía sus ánimos el disonante clamor de la multitud que los cercava para verlos, levantando a cada accidente del combate. Finalmente aviendo estado mucho tiempo dudoso en trance de la batalla, quedó la victoria por el soldado toledano. Excitose luego al punto grande alegría y aplauso del pueblo, toda edad, sexo y orden de gente, levantando al cielo las manos y las voces, y corriendo las lágrimas por sus mexillas, comenzaron a dar gracias a Dios, y a ensalzar con alabanzas el valor de su soldado, pidiendo a porfía todo bien y aumento a Dios para él. Finalmente concurrieron frequentemente a los altares de los santos a cumplir las promesas, y votos que avían hecho por su religión en aquellos mismos ritos suios 22 .

En consonancia con la tradición, la victoria se inclina de parte del defensor del rito hispano con gran entusiasmo del pueblo, pero no es aceptada por el rey. Para atenuar lo negativo de la obstinación de Alfonso a favor del rito «francés», Ortiz introduce una explicación que denota su formación jurídica: el monarca se niega a considerar el certamen de armas como «idóneo argumento del divino

20 GonZÁLVEZ RuIZ, «Cisneros y la reforma», p. 204. En el siglo XVIII Nicolás Antonio atribuyó su autoría al humanista Juan de Vergara; estudios recientes, sin embargo, se la han devuelto a nuestro canónigo; Juan Meseguer FernándeZ, «El Cardenal Jiménez de Cisneros, fundador de la Capilla Mozárabe», en Historia Mozárabe, Ponencias y comunicaciones presentadas al I Congreso Internacional de Estudios Mozárabes (Toledo 1975), Toledo 1978, p. 178; PEREDA, p. 85.

21 «El origen de estos oficios, de qué suerte ayan permanecido desde sus primitivos tiempos antiguos asta los nuestros, especialmente en esta ciudad por ser propio de este lugar, no me parece fuera de propósito referirlo»; ORTIZ, Descripción, p. 237.

22 Ibidem, p. 239. 
consejo», al tratarse de cosas sagradas ${ }^{23}$. Así pues, el fracaso del duelo da paso a la famosa ordalía del fuego, descrita con un estilo idéntico al anterior:

Finalmente se conformaron todos de común consentimiento en que después de aver implorado la divina misericordia, con oraciones y ayunos, se inquiriese su voluntad con un milagro, y se pidiese con súplices ruegos y votos, que hechando en una pyra encendida ambos misales, el toledano y el francés, el que aprovase su divino consejo, cuio uso fuese más útil a la república cristiana, esse se dignase de conservar ilesso del fuego [...] El día establecido, encendida en medio de la plaza una grande pyra, estando inumerable turba suspensa a la espectación del prodigio, se traxeron los dos misales, y después de aver hecho oración a Dios pidiendo a su magestad que lo que más le agradase que se hiciesse en aquel caso se dignase de manifestarlo a los hombres con aqual milagro, fueron ambos arrojados en medio de las llamas. Donde entonces (o maravilla estupenda!) el misal francés, se dice que esparcidas las ojas salió de en medio del fuego por sí mismo, libre del incendio. Pero el toledano tanbién incólume, se quedó en el mismo lugar donde avía sido $\operatorname{arrojado}^{24}$.

Destaquemos, en primer lugar, cómo Ortiz prepara su argumentación. La cuestión del rito no depende de una decisión humana, bien sea del rey o del pueblo. Lo fundamental es conocer la suprema voluntad divina a través de un signo portentoso, el cual acontece a la vista de todos en la ordalía del fuego. En efecto, ninguno de los dos misales se quema, aunque el romano salta fuera de las llamas mientras que el «toledano» se queda dentro de ellas. Es precisamente aquí donde Blas Ortiz altera la versión legendaria, según la cual el libro romano se consumió en la pira ${ }^{25}$. Este cambio le permite moverse en un doble nivel narrativo: el de la verosimilitud y el de la certeza. El primero le sirve para justificar la pervivencia del rito hispano en Toledo 26 ; el hecho de que ambos libros salieran indemnes daba vía libre a una «creíble» y novedosa interpretación del prodigio, en sí ambiguo, por parte del rey y sus nobles. En el segundo plano, constata simplemente el hecho histórico que se ha prolongado a lo largo de los siglos, esto es, la coexistencia de las dos liturgias:

El qual portento es creyble que el rey y los próceres reales le interpretaron assí: que el rito francés mandava Dios se publicase y ussase de el en toda España, y el toledano sólo en aquellas yglesias de Toledo donde entonces se cantava se conservase. Assí consta con certeza que por decreto del rey, con autoridad del legado y el pontífice quedó establecido.

${ }^{23}$ Idem.

${ }^{24}$ Ibidem, p. 240.

25 «Igne consumitur liber officii Gallicani et prosiliit super omnes flammas incendii, cunctis uidentibus et Deum laudantibus»; JIMÉNEZ DE RADA, lib. VI, cap. XXV, p. 208

${ }^{26}$ Resulta llamativo que Simonet suponga que los autores que afirman que ninguno de los dos libros litúrgicos se quemara lo hacen «sin duda por veneración al rito pontificio», siendo más bien lo contrario; Francisco Javier Simonet, Historia de los mozárabes de España, (Memorias de la Real Academia de la Historia XIII), Madrid 1903, p. 699.

Hispania Sacra, LIX

119, enero-junio 2007, 141-162, ISSN: 0018-215-X 
No ignoro que nuestros historiadores no han hecho mención alguna de la interpretación de este prodigio, y por esso el arzobispo de Toledo don Rodrigo no dexa ni aun lugar para dudarlo. Porque dice (si se debe dar crédito a los ejemplares) que quedando entero el misal toledano se abrassó totalmente el francés, pero que el rey demasiadamente tenaz, menospreciando el milagro, persistió en su sentencia ${ }^{27}$.

Ahora bien, Ortiz era consciente de que una historia tan conocida como la de Jiménez de Rada no se podía alterar arbitrariamente. Por eso añade a continuación dos argumentos que van a reforzar su relato: por un lado, la integridad y rectitud del monarca Alfonso VI, que en su tiempo nadie pone en duda; y por otro, la inviabilidad de una medida injusta habida cuenta de la publicidad del milagro ${ }^{28}$. Es más, el texto sugiere que el famoso refrán «allá van leyes donde quieren reyes», con su sentido malicioso original, que reflejaba la imposición regia del rito extranjero, podría haber nacido con mayor razón aun de esta interpretación de Alfonso VI que autorizaba aquella anomalía litúrgica en los templos de los mozárabes ${ }^{29}$. Aunque, nuestro canónigo vuelve a situarse de nuevo en el plano de la certeza de los hechos ${ }^{30}$.

En resumen, en la Descripción de Ortiz se manipula el material cronístico tradicional al narrar la ordalía del fuego con un evidente propósito de legitimar el motivo de la tolerancia regia y, en última instancia, la misma pervivencia del rito «toledano» mediante una intervención divina. Dicha interpretación está asentada sobre una base legendaria, alejándonos por completo de la realidad histórica. Sea o no una creación original de Blas Ortiz, este relato va a tener otros continuadores en el ámbito de Toledo.

\section{Juan de Mariana (1536-1624)}

Con el jesuita Juan de Mariana, oriundo de Talavera de la Reina, nos situamos ante un gran historiador, además de teólogo, escriturista y pensador, considerado como una de las tres aportaciones más relevantes de la Compañía al «siglo de oro» español junto a Francisco Suárez y Baltasar Gracián ${ }^{31}$. En el

\footnotetext{
27 ORTIZ, Descripción, p. 240.

28 «Pero verdaderamente no juzgo lícito atribuir al rey, varón excelente, assí en todas las regias dotes, como en la gran piedad para con Dios, tan impía y insana proterbia, ni era fácil que se quitase la turba sediciosa, aviendo sucedido tan portentoso milagro»; Ibidem, p. 240.

${ }^{29}$ Sobre el «sentido malicioso» de este conocido proverbio ha escrito Antonio G. SolaLINDE, «lla van leys do mandan reys», Revista de Filología Española 3 (1916) 298-300.

30 «Lo que consta con certeza es que aquel rito francés, o por mejor decir gregoriano, del qual ussa aora cassi toda la yglesia latina en España no fue recivido sin contienda; pero el toledano fue permitido en aquellas seis yglesias de Toledo»; ORTIZ, Descripción, pp. 240-241.

${ }^{31}$ Nazario GonZÁlez, «Mariana, Juan de», en Charles E. O’Neil y Joaquín Ma ${ }^{a}$. DomíngueZ (dirs.), Diccionario Histórico de la Compañía de Jesús. Biográfico-Temático, t. III, p. 2506.
} 
conjunto de su amplia labor historiográfica, que llevó a cabo fundamentalmente en Toledo, donde vivió desde 1574 hasta su muerte, vamos a fijarnos en su obra más destacada: Historice de rebus Hispanice libri XXX (Toledo, 1592), que él mismo vertió al castellano ante el éxito obtenido, siendo publicada nueve años después, también en Toledo, bajo el título Historia General de España, compuesta primero en latín, después vuelta al castellano ${ }^{32}$. No debemos ignorar, por otra parte, que el propósito general de la obra respondía a un «criterio básicamente informativo» y no a una intención «enteramente apologética» ${ }^{33}$, aunque ésta tiene su peso dado que por entonces se estaba configurando la leyenda negra antiespañola.

Antes de entrar en el análisis, precisemos dos aspectos del padre Mariana en su quehacer como historiador que se reflejan en su tratamiento del cambio de rito: por un lado, demuestra que más que un investigador stricto sensu es un hábil y erudito compilador con grandes valores literarios ${ }^{34}$, lo cual observamos en la incorporación de los materiales cronísticos del Ovetense ${ }^{35}$ y del Toledano ${ }^{36}$. Por otro lado, y en relación con lo anterior, sabemos que utilizó como fuentes históricas los romances y las viejas crónicas, lo que le indujo a admitir historias

${ }^{32}$ En la historiografía española esta obra se sitúa «a medio camino entre la Crónica General de Alfonso X el Sabio en el siglo XIII y la Historia General de España de Modesto la Fuente en la segunda mitad del siglo XIX»; GonZÁLEZ, p. 2506. La motivación para escribirla radica al parecer en su experiencia en el extranjero donde advirtió el desconocimiento que existía de la historia española, lo cual explica que la primera versión fuera en latín, traduciéndola posteriormente «para vulgarizarla entre los españoles»; Zacarías García VILlaDA, «El P. Juan de Mariana, historiador», Razón y Fe 24 (1924) 456.

33 José BArba-Martín, «Las dos historias de Juan de Mariana», Estudios. Filosofía-Historia-Letras 29 (1992) 51-70. Así consta en la dedicatoria a Felipe III, en la edición de 1601, cuando explica los motivos que le llevaron a escribir su historia latina: «Juntamente me convidó á tomar la pluma el deseo que conocí los años que peregriné fuera de España, en las naciones extrañas, de entender las cosas de la nuestra; los principios y medios por los que se encaminó á la grandeza que hoy tiene»; Juan de MARIANA, Historia General de España, (Biblioteca de Autores Españoles 30), Madrid 1950, p. LII.

34 Eusebio REY, «Mariana, Juan de», en Diccionario de Historia Eclesiástica de España, t. III, p. 1417; García VilladA, p. 461. Como afirma Nazario González, su argumentación, aun lejos de ser una pura construcción acumulativa, propia de las crónicas medievales, adolece de la necesaria crítica documental que arranca desde el siglo XVIII; GonZÁLEZ, p. 2506.

35 SÁnchez AlOnSo (ed.), p. 80. Este material está presente en la sección dedicada a los comienzos del reinado de Alfonso VI donde Mariana menciona «un concilio de obispos de todo el reino» celebrado en Burgos el año 1076 en el que se mandó introducir el rito romano. Entremezcla estos datos históricos, en cambio, con dos anacronismos: que la embajada enviada a Roma «para suplicar al Papa enviase un legado» fuera hecha a instancia de la reina Constanza, que aún no se había casado con Alfonso VI; y que la asamblea celebrada en aquella «ciudad cabeza de Castilla» fuera convocada por el cardenal Ricardo, «abad de San Víctor», el cual ni era aún abad de la casa marsellesa ni había venido todavía a la Península; MarianA, Historia General de España, lib. IX, cap. XI, p. 260.

36 Pierre David ya señaló esta dependencia respecto de Jiménez de Rada: «Rodrigue de Tolède, suivi par Mariana t. IX, place le duel et l'épreuve du feu à Tolède en 1086 »; Pierre DAVID, Études historiques sur la Galice et le Portugal du VIe au XIIe siècle, Lisboa-Paris 1947, p. 401, nota 2.

Hispania Sacra, LIX

119, enero-junio 2007, 141-162, ISSN: 0018-215-X 
legendarias de forma acrítica ${ }^{37}$. Esto lo vamos a verificar precisamente a propósito del relato del duelo y la ordalía del fuego.

En el capítulo 18 de su Historia, titulado Cómo se quitó el Breviario mozárabe ${ }^{38}$, advertimos inmediatamente un vivo contraste con el estilo de Blas Ortiz. El jesuita tiende a ser mucho más conciso y sobrio. Atribuye la decisión de «quitar el Misal y Breviario gótico» al arzobispo don Bernardo y al legado pontificio Ricardo. Menciona también anteriores intentos de abolir el rito que habían fracasado, hecho que comenta con una moraleja de su estilo ${ }^{39}$. Después de esto, llegamos a la narración de los juicios de Dios, que Mariana admite, aunque los juzga con la mentalidad propia de un discípulo del Renacimiento ${ }^{40}$. Acerca del duelo indiquemos simplemente, además de su laconismo ${ }^{41}$, que el soldado que defendía «el Breviario antiguo» se llamaba Juan Ruiz, nombre que no aparece ni en la Crónica Najerense, ni en el Toledano, ni en la Primera crónica general de España. Respecto a la ordalía del fuego, merece la pena leer todo el texto, ya que a partir de ella se explica de nuevo el origen de la dualidad ritual:

Encendióse una hoguera en la plaza, y el Breviario romano y gótico se echaron en el fuego. El romano saltó del fuego, pero chamuscado. Apellidaba el pueblo victoria á causa que el otro, aunque estuvo por gran espacio en el fuego, salió sin lesión alguna, principalmente que el arzobispo don Rodrigo dice que saltó el romano, pero chamuscado. Advierto que en el texto del Arzobispo los puntos se deben reformar conforme á este sentido. Todavía el Rey, como juez, pronunció sentencia en que se declaraba que el un Breviario y el otro agradaban á Dios, pues ambos salieron sanos y sin daño de la hoguera; lo cual el pueblo se dejó persuadir. Concluyóse el pleito, y concertaron que en las iglesias antiguas

37 García VilladA, p. 459; Emilio Mitre, «La historiografía sobre la Edad Media», en José ANDRÉS-GALLEGO (coord.), Historia de la historiografía española, Madrid 1999, p. 78. Un juicio similar se encuentra en Benito SÁnchez Alonso, Historia de la historiografía española II, Madrid 1944, p. 172 .

${ }^{38}$ MarianA, Historia General de España, lib. IX, cap. XVIII, pp. 270-271.

39 «Habíase procurado muchas veces esto mismo, pero no tuvo efecto, porque la gente mas gustaba de lo antiguo, y no hay cosa que con mas firmeza se defienda que lo que tiene color de religion»; Ibidem, p. 270. El fin pragmático que tiene la historia (maestra de la vida) para el jesuita se refleja en frecuentes consideraciones prácticas de este tipo; García ViLladA, p. 456.

40 Con motivo del duelo escribe: «como gente guerrera, quisieron esta diferencia se determinase por las armas»; y sobre la prueba del fuego añade: «Tales eran las costumbres de aquellos tiempos groseros y salvajes y no muy medidos con la regla de piedad cristiana». No olvidemos que los hombres del Renacimiento y más aún los de la Ilustración contribuyeron «a forjar esa antinomia Medievo-Tiempos Modernos que reducía el primero a la categoría de época de la barbarie, la superstición y el dominio absoluto de la Iglesia Católica»; Mitre, p. 74.

${ }^{41}$ Nuestro jesuita, en efecto, lo resume en dos frases: «El día señalado dos soldados escogidos de ambas partes lidiaron sobre esta querella en un palenque y hicieron campo; venció el que defendía el Breviario antiguo, llamado Juan Ruiz»; Mariana, Historia General de España, lib. IX, cap. XVIII, pp. $270-271$. 
que llaman mozárabes se conservase el Breviario antiguo. Concordia que se guarda hoy dia en ciertas fiestas del año, que se hacen en los dichos templos los oficios á la manera de los mozárabes. Tambien hay una capilla dentro de la iglesia mayor, en la cual hay cierto número de capellanes mozárabes, que dotó de su hacienda el cardenal fray Francisco Jimenez, porque no se perdiese la memoria de cosa tan señalada y de rezo tan antiguo. Estos rezan y dicen misa conforme al Misal y Breviario antiguo. En los demás templos hechos de nuevo en Toledo se ordenó se rezase y dijese misa conforme al uso romano ${ }^{42}$.

Señalemos, primeramente, la insistencia de Mariana en la rectificación que se ha de obrar en la crónica de Jiménez de Rada. El libro romano no se consumió, sino que tan sólo se chamuscó. En realidad, la finalidad pragmática que la historia tiene para Mariana le lleva a exponer sus propias ideas sobre sucesos o resoluciones de los personajes que en ellos intervinieron ${ }^{43}$. Por ello no duda en modificar el texto de $R H$ en vistas a justificar la dualidad ritual en idéntica línea que Blas Ortiz: ambos ritos son aceptados y autorizados legítimamente porque ninguno de los dos arde en la prueba del fuego. Por ello el rey ${ }^{44}$, como intérprete de la voluntad divina, juzga que los dos son gratos a Dios y que el rito «gótico», usado «en España desde muy antiguos tiempos por autoridad de los santos Isidoro, Ildefonso y Juliano», debe seguir celebrándose en las parroquias en que había sobrevivido durante la dominación árabe. Notemos, a su vez, que el historiador jesuita, testigo directo de los frutos de la reforma de Cisneros, comparte la veneración general por «la memoria de cosa tan señalada y de rezo tan antiguo».

Ahora bien, ¿se inspiró Mariana para su relato en la Descripción de Blas Ortiz? Es probable que así fuera. Lo más importante, sin embargo, no es que este argumento de legitimación parta de la obra del canónigo, sino que con su incorporación en la Historia de Mariana trascendía ampliamente el ámbito local toledano y su difusión alcanzaba unos límites muy superiores. De hecho, a comienzos del siglo XVII, historiadores destacados, como el benedictino Prudencio de Sandoval (ca. 1551-1620)45, habían asumido esta misma idea.

${ }^{42}$ Ibidem, p. 271.

${ }^{43}$ García Villada, p. 456.

${ }^{44}$ La figura de Alfonso merece el siguiente juicio de Mariana: «Príncipe más venturoso en la guerra que en el tiempo de la paz y en sucesión, no menos admirable en las borrascas que cuando soplaba el viento favorable y todo se le hacía á su voluntad»; MARIANA, Historia General de España, lib. IX, cap. XX, p. 274.

45 Prudencio de Sandoval, Historia de los Reyes de Castilla y de León... Pamplona 1615. He consultado la edición impresa en Pamplona, por Carlos de Labàyen, 1634, f. 65, a partir del ejemplar conservado en Cantoblanco, Universidad Pontificia Comillas (fondo antiguo), sign. 3962.

Hispania Sacra, LIX

119, enero-junio 2007, 141-162, ISSN: 0018-215-X 


\section{Francisco de Pisa (1534-1616)}

Dentro de esta línea de interpretación hemos de considerar todavía a un tercer autor. Se trata de Francisco de Pisa ${ }^{46}$, cuya obra es cronológicamente posterior a la del padre Mariana, aunque éste le sobrevivió ocho años. No cabe duda de que el doctor Pisa es quien más estrechamente vinculado estuvo al rito «mozárabe» de cuantos estudiamos. Eclesiástico de gran cultura, historiador y canonista, fue durante muchos años rector de la parroquia mozárabe de las santas Justa y Rufina ${ }^{47}$ y capellán mayor de la capilla del Corpus Christi. Su obra más ambiciosa e importante, según la opinión de Gómez-Menor, es la Descripción de la Imperial Ciudad de Toledo ${ }^{48}$, la cual fue costeada por él mismo, saliendo a la luz en 1605 y, en edición póstuma por Tomás Tamayo de Vargas, en 161749.

Como ya indicamos, este capellán mozárabe dedica un capítulo específico al cambio de liturgia, al igual que Alcocer y Mariana, que lleva por título De la mudança o trueco del oficio diuino Gothico, por el Romano, o Gallicano ${ }^{50}$. Como introducción se incluye de nuevo la intervención romana en la vida de la Iglesia peninsular con el envío del cardenal Ricardo. Luego, en dependencia de $R H$, Pisa plantea el problema del rito lógicamente en el escenario toledano, poniendo de relieve dos tópicos: la antigüedad y valor de la liturgia que se quería suplantar y la influencia de la esposa francesa de Alfonso VI:

Pero antes de la reuocacion sucedio vna dificultad en esta ciudad, que como hasta entonces se huuiesse vsado en Toledo, y en toda España el oficio diuino Gothico, llamado Muzarabe, o Toledano, ordenado por san Isidoro Arçobispo de Seuilla, y acrecentado por san Illefonso, y san Iulian Arçobispos desta ciudad, que es muy diferente del Gregoriano, o Romano: el Rey don Alonso induzido por la reyna su muger, llamada doña Costança, o

\footnotetext{
46 José GóMEz-MenOR, «El doctor Francisco de Pisa, capellán mayor de la Capilla mozárabe (vida y obras)», Historia Mozárabe, Ponencias y comunicaciones presentadas al I Congreso Internacional de Estudios Mozárabes (Toledo 1975), Toledo 1978, pp. 269-277; este trabajo se encuentra también en «Pisa, Francisco de», en Diccionario de Historia Eclesiástica de España, Suplemento I, pp. 615-616. Acerca de algunas vicisitudes de su vida y de las dificultades de la edición de su Historia de Toledo puede verse igualmente Hilario RODRíGUEZ DE GRACIA, «Notas para la biografía de dos toledanos ilustres», Anales toledanos 22 (1986) 19-57.

${ }^{47}$ Recordemos que este templo, considerado la «catedral mozárabe», tuvo una importancia singular por ser el que aportó los libros de su archivo para la restauración de Cisneros. En el año 1530 se hicieron en él obras de adaptación y embellecimiento.

${ }^{48}$ Gómez-Menor, p. 276. El título completo de la obra es: Descripcion de la Imperial Civdad de Toledo, y historia de sus antiguedades, y grandeza, y cosas memorables que en ella han acontecido, de los Reyes que la han señoreado, y gouernado en sucession de tiempos: y de los Arçobispos de Toledo, principalmente de los mas celebrados. Primera parte. Repartida en cinco libros con la historia de Santa Leocadia. Dirigida y dedicada al Senado de la misma Ciudad, Toledo, por Pedro Rodríguez, 1605 (ed. facsímil, Toledo 1974).

${ }^{49}$ SÁnCHEZ Alonso, Historia de la historiografía II, p. 232.

${ }^{50}$ PISA, Descripción, lib. III, cap. XXII, ff. 156r-157.
} 
segun otros doña Beatriz, de nacion Francesa, hizo instancia con el Legado Apostolico, y con el Primado don Bernardo, que dexado este oficio Toledano, se introduxesse y celebrasse el Romano, que por otro nombre llamauan Galicano, por estar recebido y vsado en Francia: al qual oficio ella estaua habituada a oyr ${ }^{51}$.

Tras este planteamiento sigue la enconada resistencia del «clero, y caualleria, y pueblo desta ciudad», lo cual fuerza la celebración del duelo ${ }^{52}$. De acuerdo con la tradición épica, el caballero defensor del rito romano es derrotado, pero el rey y la reina fuerzan un segundo juicio divino. Al igual que Blas Ortiz, Pisa refiere que son dos misales, en lugar de los dos breviarios de Mariana, los que se arrojan al fuego. En líneas generales, todo concuerda con las dos narraciones vistas hasta ahora:

Precediendo pues ayunos, y oraciones, y encendido fuego en medio de la plaça, y echados en el los dos libros Missales, vno de cada oficio, escriuen algunos, que el Romano, o Frances salto fuera del fuego, y el Toledano, o Gothico quedó dentro en el mucho tiempo sin quemarse, ni recibir ningun daño. Lo qual parece daua a entender que de ambos oficios era Dios seruido, y agradado, pues los dos quedaron sin lesion. Esta manera de dezir escriuen muchos autores en lengua Latina, y en la Castellana: de los quales es vno fray Alonso de Castro lib. I. de iusta haret. punit. cap. 7. Blas Ortiz, Pedro de Alcozer, y el Maestro Aluar Gomez en la vida de don fray Francisco Ximenez. El Rey y sus ministros dauan al milagro esta declaracion, o interpretacion, que en Toledo se vsasse siempre del oficio Toledano, que es el que se quedó dentro del fuego, en las seys parrochias antiguas, que se llaman Muzarabes, y el Romano que salto fuera del fuego, se vsasse en las demas parrochias della, y de todo el reyno. Y esta moderacion, y concordia se puso por ley y decreto, establecido por el Legado del Papa, y por el Arcobispo, y hasta oy se guarda ${ }^{53}$.

Es evidente que Francisco de Pisa, sabedor de haber alterado el relato de $R H$, trata de conferir autoridad a su versión citando a cuatro autores que comparten «esta manera de decir». Ortiz, Alcocer, Gómez de Castro y Alonso de Castro (1495-1558) ${ }^{54}$ concuerdan en que ninguno de los libros fue consumido

\footnotetext{
51 Ibidem, f. 157.

${ }^{52} \mathrm{Al}$ igual que sucede en la obra de Mariana, Francisco de Pisa hace un juicio negativo de este tipo de pruebas, hechas «conforme a la rudeza, y mal vso de aquellos tiempos»; Idem.

53 Ibidem, ff. 157-157v.

${ }^{54}$ Así lo narra este franciscano, jurista y predicador, perteneciente a la segunda generación de grandes teólogos españoles, al censurar al dominico alemán Bernardo de Luxemburgo por haber incluido a los mozárabes en su lista de herejes en 1547: «Illis autem omnino contradicentibus ex communi omnium consensu decretum est, vt magno aliquo, atque vasto igne accenso duo libri in illum proiicerentur, quorum vnus Missæ officium contineret iuxta ritum Gallicum, alter iuxta antiquum Hispaniæ morem. Et illo die, quo hæc facienda erant, indictum est a Bernardo Archiepiscopo Toletano generale ieiunium (res enim hæc Toleti agebatur) vt per ieiunis meritum Deus exoratus reuelare vellet per miraculi ostensionem, quid esset agendum. Proiiciuntur duo illi libri in medio ignis, \& liber, qui Gallicum, siue Romanum tenebat officium, cœpit ex igne stridorem quendam facere, \& statim saltu quodam ab igne resi-
}

Hispania Sacra, LIX

119, enero-junio 2007, 141-162, ISSN: 0018-215-X 
por el fuego. Lo cual, en realidad, no es cierto en el caso de Alvar Gómez de Castro que no narra los detalles de la ordalía, como veremos. Es muy probable que la Descripción de Ortiz sea aquí la fuente de Francisco de Pisa, porque solamente en ella se explica a partir de este milagro legendario la dualidad ritual de Toledo.

Fijémonos también en un cierto simbolismo utilizado en la interpretación del prodigio y en la consiguiente aplicación. El monarca y sus ministros consideran que el fuego simboliza a la ciudad de Toledo, por lo cual deciden «que en Toledo se vsasse siempre del oficio Toledano, que es el que se quedó dentro». Por su parte, sobre el misal romano, que había saltado fuera, deciden que «se vsasse en las demas parrochias della [=ciudad de Toledo], y de todo el reyno».

Todavía Pisa insiste en justificar dónde contradice al Toledano y por qué lo hace. Con notable audacia nuestro autor afirma que, de seguir al arzobispo don Rodrigo, la figura de Alfonso VI, «vn Principe tan Christiano y prudente», quedaría desacreditada. Se trata de un razonamiento análogo al de Ortiz, basado en la integridad y rectitud del monarca. Pero además, como experto jurista, transforma el sentido del proverbio «Alla van leyes...», al considerarlo más idóneo a su narración, ya que en un caso de duda como éste es al rey a quien compete interpretar las leyes con sabiduría y en vistas del bien común:

Bien se que el Arçobispo don Rodrigo cuenta este milagro de otra suerte, diziendo que el libro del oficio Romano se auia abrasado, quedando entero el Toledano, y que con ser assi toda via el Rey se quedó firme, y pertinaz en su parecer, y proposito: y que de ay nacio, y tuuo origen el prouerbio vulgar: Alla van leyes do quieren Reyes. Pero los que tienen el parecer contrario pueden dar buen sentido a este prouerbio: conuiene a saber, que las leyes en caso de duda se deuen interpretar segun el arbitrio del Rey, y legislador, para mayor prouecho, paz, y sossiego del pueblo, como aqui se hizo: porque el milagro a las dos partes fauorecia, y por tanto se deuia interpretar por vn medio sabio: y de vn Principe tan Christiano y prudente no se deue sospechar ninguna pertinacia, o indeuida dureza, mayormente en cosas de piedad, y religion ${ }^{55}$.

A diferencia de Blas Ortiz, la interpretación de Pisa no expresa «el verdadero sentido malicioso» que tuvo desde su origen este dicho nacido -según Jiménez de Rada- «como comentario al abuso cometido por el rey Alfonso VI al imponer el oficio galicano sobre el toledano o mozárabe, a pesar de las pruebas y

liit. Liber autem qui officium Gotthicum siue Mossarabum continebat, perseuerauit absque vlla læsione in medio ignis quousque ille fuit prorsus extinctus»; Alonso de CASTRO, De iusta hareticorum punitione libri tres, Salamanca, por Juan de Junta, 1547, lib. I, cap. VII, ff. 26-27. He consultado el ejemplar conservado en Cantoblanco, Universidad Pontificia Comillas (fondo antiguo), sign. XVI-606. En este capítulo, Castro deja claro que los mozárabes no son herejes ni sospechosos de herejía, como tampoco lo son sus ceremonias litúrgicas.

55 PISA, Descripción, lib. III, cap. XXII, f. 157v. 
milagros acaecidos en contra de aquella liturgia» ${ }^{56}$. Debemos concluir, por tanto, que el doctor Francisco de Pisa, pese a ser deudor de Alcocer e insistir una y otra vez en la admirable firmeza de la fe de la primitiva comunidad mozárabe ${ }^{57}$, opta por la interpretación legendaria, creada a partir de la ordalía del fuego, perfeccionándola con algunos argumentos de carácter jurídico que le resultaban familiares.

\section{LA INTERPRETACIÓN RETRIBUTIVA EN MEMORIA DE LAS SEIS IGLESIAS}

\section{Pedro de Alcocer (s. XV-XVI)}

Pedro de Alcocer, historiador y anticuario toledano, es uno de los primeros representantes de la historiografía renacentista hispana, pese a que continúa siendo un autor poco estudiado ${ }^{58}$. No obstante la atribución hecha por Tamayo de Vargas a Juan de Vergara, sabemos con certeza que Alcocer es el autor de una obra de gran erudición en la que describe la historia de Toledo desde su fundación hasta su época ${ }^{59}$, y que tiene por modelo la Crónica General de España (Zamora, 1543) del historiador zamorano Florián de Ocampo (ca. 1499$1558)^{60}$. Al igual que Juan de Mariana y Francisco de Pisa, Alcocer dedica en su Historia o Descripción de la Imperial ciudad de Toledo un capítulo a la abolición de la liturgia hispánica, con la diferencia de que incluye en él un brevísimo relato de la dedicación de la catedral primada. El título refleja los dos temas tratados: De como el Arçobispo don Bernardo celebro Concilio en esta sancta yglesia, en que se hizo la dedicacion della y se quito el oficio Muçarabe ${ }^{61}$.

\footnotetext{
56 Solalinde, p. 299.

57 Es precisamente aquí donde Richard Hitchcock ve una defensa contra las «actitudes antagónicas» hacia los mozárabes. Algunos textos ilustrativos sobre este punto en la nota 67.

${ }^{58}$ Sánchez Alonso apenas le dedica una página por su Relación de las Comunidades de España al tratar de las obras sobre sucesos particulares entre 1480 y 1543; SÁNCHEZ AlOnso, Historia de la historiografía $\mathrm{I}, \mathrm{p} .415$.

59 Pedro de AlCOCER, Hystoria, o descripcion de la Imperial cibdad de Toledo. Con todas las cosas acontecidas en ella, desde su principio, y fundacion. Adonde se tocan, y refieren muchas antiguedades, y cosas notables de la Hystoria general de España. Agora nueuamente impressa, Toledo, por Juan Ferrer, 1554 (ed. facsímil, Toledo 1973). Según Kagan, Alcocer habría comenzado ya a componer su obra en 1541; Richard L. KAGAN, «Clio and the Crown: Writing History in Habsburg Spain», Spain, Europe and the Atlantic World. Essays in Honour of John H. Elliot, Cambridge, 1996, pp. 73-99.

${ }^{60}$ Así se afirma en la presentación anónima del artículo Pedro de ALCOCER, «Historia de Toledo», Toletum, $2^{\mathrm{a}}$ época, 1 (1955) 264-265. Aquí se reconoce también que los capítulos de la parte antigua y medieval «están nutridos por las historias de D. Rodrigo Jiménez de Rada y D. Lucas de Tuy, sin que aporten novedad particular»; Ibidem, p. 266.
}

${ }^{61}$ AlCOCER, Historia, lib. I, cap. LXVIII, ff. 55v-56v .

Hispania Sacra, LIX

119, enero-junio 2007, 141-162, ISSN: 0018-215-X 
Alcocer plantea la crisis del rito presentando, una vez más, como factor desencadenante la actitud de la reina Constanza. Ella, en efecto, es quien induce al rey, y éste al legado apostólico y al arzobispo don Bernardo, quienes mandan el uso del nuevo rito «de parte del Papa»:

Y como avn hasta entonces se vsasse en toda España, el officio Gothico, que vulgarmente llaman Muçarabe, que sant Leandro, y sant Ysidoro arçobispos de Seuilla compusieron (que avnque es deuotissimo, es en muchas cosas differente del Romano, assi en el celebrar de las missas, como en la orden de rezar) mouido el rey, por induzimiento de la reyna doña Costança su muger, que era Francesa (adonde el dicho oficio Romano ya se vsaua) procuro que el legado Apostolico, y el Arçobispo de Toledo, compeliessen a todos los de su reyno, a que dexassen el dicho oficio Gothico, y vsassen desde en adelante del Romano: y como ellos de parte del Papa, les mandassen que lo hiziessen assi: so graues penas y censuras, el clero y pueblo christiano, puso a ello sus suficientes escusas: no obstante, las quales, el rey les mando que toda via cumpliesen los mandamientos Apostoli$\cos$, sin detenimiento alguno ${ }^{62}$.

A raíz de los altercados producidos en la ciudad se acuerda el «juyzio de batalla»-como en los demás textos-, narrado aquí de forma escueta. Indiquemos que Alcocer afirma que el rey designó un «escudero» o luchador por su parte y «los obispos y clerecía» otro, afirmación que manifiesta la idea errónea de que la Iglesia hispana en su totalidad se oponía a la adopción del rito romano ${ }^{63}$. Tras la derrota de su combatiente, el rey permanece inamovible en su opinión, y por ello se acuerda un «juyzio miragloso» con dos misales que se han de arrojar al fuego para que Dios muestre «de qual oficio era mas seruido»:

Y auiendo precedido ayuno y oracion, fueron echados en vn gran fuego, que para aquello fue hecho dos missales, de cada oficio el suyo: y el missal del oficio Romano, quedo en el fuego, sin quemarse: y el otro salio del, sin recibir daño alguno: loando todos a nuestro señor que tal marauilla mostro. Mas ni por esto el brauo coraçon del rey fue amansado, antes insistio de nueuo en su primera opinion de tal manera, que por ninguna cosa pudo della ser apartado, hasta que su mandamiento fue cumplido, recibiendo todos: avnque contra su voluntad, lo que el legado, y Arçobispo de parte del Papa les mandaron: y desde entonces se vsa en España el oficio Romano ${ }^{64}$.

Algunas variantes respecto a los autores ya estudiados merecen un comentario. No deja de ser llamativo que el misal romano es ahora el que permanece en el fuego mientras que el hispano sale fuera, ambos sin quemarse. ¿Se trata de

\footnotetext{
62 Ibidem, f. 56.

${ }^{63}$ Ciertamente, Gregorio VII no se vio solo en la cuestión ritual castellano-leonesa, sino que contó con el apoyo de algunos obispos, junto al del monacato cluniacense. El planteamiento del cambio de liturgia en el que la Iglesia hispana en su totalidad se sitúa en el bando aferrado al rito autóctono no deja de ser una simplificación de la realidad histórica; RUBIO SADIA, Las órdenes religiosas, pp. 48-49.

${ }^{64}$ AlCOCER, Historia, lib. I, cap. LXVIII, f. 56.
} 
un lapsus de Alcocer? Lo ignoramos. Es cierto que el resultado de aquella prueba resultó milagroso, pero el historiador tampoco indica que la voluntad divina se manifestara a favor de alguna de las dos liturgias. El rey se mantiene, pues, en su inapelable decisión, si bien se percibe en el texto una cierta indeterminación acerca de quién decide, en último término, la introducción del rito romano. El rey manda, pero también manda el papa a través de su legado y del arzobispo. A continuación se incluye la justificación de la particular dualidad de Toledo:

Avnque por voluntad del rey, quedaron en esta cibdad las seys yglesias, que auemos dicho (que los Moros dexaron en ella) en memoria que ellos dexaron las mismas a los christianos al tiempo que esta cibdad vino a su poder: en las quales, el dicho oficio Muçarabe se vsa, hasta oy donde ay sus curas y perrochianos Muçarabes ${ }^{65}$.

Alcocer articula dos elementos en su argumentación: por una parte, acentúa la voluntad regia que, sin embargo, podría parecernos contradictoria, puesto que esa misma voluntad se había obstinado en contra de la liturgia autóctona. Por eso inmediatamente se añade una motivación de carácter conmemorativo, al autorizarse el rito en las seis iglesias mozárabes ${ }^{66}$, en recuerdo de que los musulmanes habían dejado esas mismas a los cristianos cuando se apoderaron de la ciudad. De acuerdo con las claves hermenéuticas arriba citadas, la tolerancia parece tener aquí su legitimación en la recompensa regia a la firmeza y fidelidad de la mozarabía toledana, que había perseverado durante siglos en la fe sin desviarse, a pesar de vivir en medio de un clima hostil ${ }^{67}$. Se trata de un ar-

65 Idem.

${ }^{66}$ En realidad, la primera lista hace referencia a siete iglesias: «Item que tuuiessen dentro en la cibdad siete yglesias: en que pudiessen celebrar missas y los otros diuinos oficios públicamente: las quales yglesias fueron estas. Sant Lucas, sancta Iusta, sancto Torcazo, sant Marcos, sant Olalla, sant Sebastian, y sancta Maria del Carmen: y escogieron las ansi vnas ta apartadas de otras, porque casi toda la cibdad quedo llena de Christianos»; Ibidem, lib. I, cap. XLII, f. 39. Pero habla finalmente de seis, porque la del Carmen no quedó como parroquia mozárabe, sino como ermita; Ibidem, cap. LXVIII, f. 56v.

${ }^{67}$ Ése es el motivo fundamental por el que Alfonso VI les otorgó importantes privilegios: «[Dio privilegios] muy mayores a los Christianos llamados Muçarabes que en ella [=Toledo] hallo: porque como buenos auian perseuerado siempre, ellos y sus predecessores en nuestra sancta fee catholica, sin auer sido corrompidos de la secta y desonesto biuir de los Moros: cuya descendencia dura avn hasta oy en esta cibdad: avnque por las mudanças que las cosas en ella han hecho, se han mezclado vnos con otros: de manera que este nombre de Muçarabes esta ya casi del todo deshecho»; Ibidem, lib. I, cap. LXVI, ff. 54-54v. Un párrafo paralelo se encuentra en PISA, Descripción, lib. III, cap. XVIII, f. 151․ En otro lugar, este mismo autor escribe: «Y aun destos mismos Christianos de entonces, procediendo de vna generacion en otra, han quedado hasta nuestros tiempos algunos linages, y vezinos de Toledo, parrochianos de algunas de las seys yglesias sobredichas, teniendose por nobleza venir de aquellos Christianos antiguos, que tuuieron tanta firmeza en la Fè [...] En aquellos antiguos Muzarabes que quedaron mezclados con los Moros, es mucho de estimar la constancia y firmeza que tuuieron en la Fè de Iesu Christo, pues en medio de la mala nacion, lucian y resplandecian, y viuiendo entre infieles, debaxo de cuyo yugo recebian malos tratamientos, claramente se entiende que estauan aparejados a padecer

Hispania Sacra, LIX

119, enero-junio 2007, 141-162, ISSN: 0018-215-X 
gumento de tipo retributivo en una situación excepcional. ¿Existe un propósito de fondo de «demostrar que a los mozárabes no se les debía tachar de gente contaminada por creencias y prácticas no católicas»? ${ }^{68}$ Dejamos abierta esta hipótesis, aunque -a nuestro parecer- es difícil creer que en los años previos a 1554 Alcocer percibiera en Toledo un clima hostil a dicha comunidad y buscara rebatirla. En la parte final de nuestro capítulo, encontramos también una breve pero significativa alusión a la restauración cisneriana, cuyo objetivo no es otro que asegurar la supervivencia del rito hispánico ${ }^{69}$.

\section{LA PERSISTENCIA RITUAL COMO DISPOSICIÓN CONCILIADORA}

\section{Alvar Gómez de Castro (1515-1580)}

El tramo final de nuestro recorrido historiográfico fija nuestra atención en uno de los humanistas toledanos más destacados y, por desgracia, también olvidados. Desde 1549 la vida del maestro Alvar Gómez de Castro transcurrió, después de su etapa docente en Alcalá, en la ciudad de Toledo, donde asumió la cátedra de retórica y griego en el Colegio de Santa Catalina durante 31 años, lo que le «permitió participar de la pasión erudita y anticuaria propia de la época y de la ciudad en la que se encontraba» ${ }^{70}$. Fruto del encargo hecho por la propia universidad de Alcalá a principios de 1566 nació su De rebus gestis a Francisco Ximenio Cisnerio, Archiepiscopo Toletano, libri octo (Alcalá, 1569) $)^{71}$, que no sólo es considerada su obra más importante ${ }^{72}$, sino que constituye además una

muerte, y martyrio, antes que dexar el culto diuino, y religion Christiana: y de hecho algunos huuo que le padecieron, y otros por lo menos resplandecieron en santidad de vida»; Ibidem, lib. II, cap. XXXVI, fol. 126.

${ }^{68}$ НiтсHCOCK, p. 498.

69 «Y porque este antiguo y deuoto oficio estaua en nuestros dias casi perdido, el reuerendissimo Cardenal don fray Francisco Ximenez arçobispo de Toledo, puso en vna Capilla desta sancta yglesia, que el hizo edificar, 13. capellanes (con vno mayor) que vsan este oficio Muçarabe, en las misas y en todos los otros oficios diuinos: y dotolos de rentas decentes: porque esta memoria durasse para siempre» AlCOCER, Historia, lib. I, cap. LXVIII, f. 56-56v. Tal era, en efecto, la verdadera finalidad de Cisneros según testimonia su criado Juan de Vallejo; Meseguer FernándeZ, p. 149.

${ }^{70}$ Esther SÁNCHEZ MEdina, «El maestro Alvar Gómez de Castro y la Epigrafía latina», Humanismo y pervivencia del Mundo Clásico, III/1 (2002) 438.

${ }^{71}$ Citaremos esta obra a partir de la edición castellana: Alvar GómEz DE CASTRO, De las hazañas de Francisco Jiménez de Cisneros, edición, traducción y notas por José Oroz RetA, Madrid 1984.

72 Antonio Alvar EzQuerra, Acercamiento a la poesía latina de Alvar Gómez de Castro: Ensayo de una biografía y edición de su poesía latina, Tesis doctoral defendida en la Universidad Complutense, Madrid 1980, t. I, p. 177. Un juicio positivo también en SÁncheZ Alonso, Historia de la historiografía II, p. 72. Sobre su merecido título de humanista véase Antonio AlVAR EZQUERRA, «Alvar Gómez de Castro, humanista», Revista de Filología Española, 62 (1982) 193-210. 
de las dos fuentes principales para conocer la vida y la obra del insigne cardenal de Toledo ${ }^{73}$. Estamos, por tanto, no ante una historia general de España, ni de Toledo o su catedral, sino ante la biografía del gran protagonista de la reforma del rito hispánico, elaborada a partir de la documentación de primera mano del que fuera secretario de Cisneros, Juan de Vergara ${ }^{74}$.

En la sección final del libro II, que el profesor Oroz Reta titula en su edición Actividades varias del Cardenal, Gómez de Castro narra la restauración de la antigua liturgia, que considera -como ya indicamos- una «empresa merecedora de grandes elogios» y un «asunto de tanta loa y magnificencia» ${ }^{75}$. No cabe duda de que dicha restauración constituye una de las hazañas del insigne prelado franciscano. La finalidad, por su parte, no era sino salvaguardar la práctica de un rito que en aquel momento había cobrado una celebridad excepcional ${ }^{76}$.

La descripción de los distintos pasos de la reforma cisneriana está precedida por un excursus de carácter histórico en el cual se encuadra el texto que nos interesa ${ }^{77}$. Remarquemos que lo que nuestro humanista denomina una «historia de los godos» en realidad se convierte en una breve historia de la liturgia hispánica. Pero, a diferencia de los casos anteriores, al llegar a la toma de Toledo no se detiene en recrear los juicios divinos, sino que remite a «otros autores». Leamos el relato en cuestión:

Reconquistada finalmente la ciudad por la gracia de Dios y la voluntad dichosa del Rey Alfonso, hijo del gran Fernando, al estudiarse la instauración y restablecimiento del culto en la misma, el Rey, por consejo del Abad Ricardo de Marsella y la constante instigación de su esposa, la Reina Constancia, dio preferencia a la Liturgia establecida en otro tiempo por San Gregorio sobre la Toledana, aunque la población decía a gritos que se abolía con la máxima injusticia el uso de su Liturgia, mantenida tantos siglos en medio de extranjeros. Los relatos sobre un combate singular entre soldados luchando uno por los ritos Góticos y el otro por los Gregorianos, y sobre una pira levantada en el centro de la plaza de Toledo, a la que se echaron ejemplares de ambos oficios Sacros, podrán leerse en otros autores que escribieron sobre el asunto con más detalle y amplitud ${ }^{78}$.

73 Oroz Reta (ed.), p. 10.

${ }^{74}$ La relación personal de Gómez de Castro con el anciano Juan de Vergara queda consignada en el prólogo del primero; Gómez DE CASTRO, De las hazañas, pp. 24-27.

75 Ibidem, p. 121.

76 «Jiménez, tras haber tenido acceso a tales volúmenes [los de la liturgia hispánica de la catedral toledana] informado por completo de la situación [...] juzgó ser una grave injusticia el que ceremonias tan santas de los antiguos hispanos, establecidas por hombres ilustres y respaldadas por el testimonio de milagros, hubieran caído en tal desuso, que parecía iban a desaparecer de un momento a otro»; Ibidem, p. 125.

77 «Antes de exponer lo que hizo Jiménez en relación a estos volúmenes, debo decir unas palabras sobre la Historia de los Godos»; Ibidem, p. 123.

${ }^{78}$ Ibidem, p. 124.

Hispania Sacra, LIX

119, enero-junio 2007, 141-162, ISSN: 0018-215-X 
Gómez de Castro no se detiene en repetir unas historias de sobra conocidas. Tal vez, podríamos sospechar que lo hace porque no las consideraba creíbles, pero en realidad les confiere valor indirectamente en un pasaje posterior, en el que afirma que las santas ceremonias de los antiguos hispanos fueron «establecidas por hombres ilustres» y estaban «respaldadas por el testimonio de milagros» ${ }^{79}$. No cabe duda de que en esta frase se refiere al relato épico. Con todo, el biógrafo de Cisneros no utiliza este material historiográfico para legitimar la dualidad litúrgica. En Toledo la liturgia no romana se autorizó con el propósito y la necesidad de pacificar a «las turbas», muy alteradas por una decisión que consideraban injusta:

Con todo, el Rey para apaciguar los ánimos de las turbas que seguían vociferando porque les arrebataban su Liturgia, al establecerse en la ciudad recién conquistada [...] las llamadas iglesias pareciales, vulgo parroquiales [...] no se determinó territorio solamente a seis iglesias, en las que se había mantenido el rito Isidoriano durante tantos años, incluso entre enemigos, sino que los Mozárabes y sus descendientes, mientras habitasen en la región de Toledo, dentro o fuera de la ciudad, fueron asignados a cada una de las iglesias como si fuesen parroquianos y del mismo sector, con la concesión de inmunidades y privilegios especiales ${ }^{80}$.

En cierta medida, esta argumentación nos acerca algo más a los hechos históricos. Tras la reconquista, en efecto, los mozárabes toledanos pudieron experimentar una fuerte contrariedad viendo que «su liturgia quedaba desterrada y la dirección eclesiástica era ejercida no por mozárabes ni aun siquiera por españoles, sino por individuos venidos de Francia» ${ }^{81}$. No obstante, conviene tener en cuenta que aquella comunidad cristiana, en el momento de entrar a formar parte del reino castellano-leonés, se hallaba mermada y debilitada desde el punto de vista cultural e incluso litúrgico ${ }^{82}$. La tolerancia impuesta por Alfonso era una medida extrema de benevolencia para evitar un vacío poblacional ${ }^{83} \mathrm{y}$, en cierto modo, era también una disposición pacificadora.

\footnotetext{
79 Ibidem, p. 125.

${ }^{80}$ Ibidem, pp. 124-125.

${ }^{81}$ Rivera ReCio, La Iglesia de Toledo I, p. 208.

82 Así se deduce del estudio del corpus de códices litúrgicos mozárabes toledanos. La reacción, sin embargo, fue enérgica tal como lo prueba la actividad escritoria de los siglos XII y XIII. A propósito de esto Díaz y Díaz escribe que «los códices litúrgicos de las parroquias mozárabes, nos ponen en contacto con una especie de resurgimiento de la vieja liturgia por obra de la comunidad toledana que descubrió en ello un síntoma de su personalidad social y religiosa»; Manuel C. DíAZ y DíAZ, «Breves notas sobre los mozárabes de Toledo», Estudios sobre Alfonso VI y la reconquista de Toledo, Actas del II Congreso Internacional de Estudios Mozárabes (Toledo 20-26 mayo 1985), vol. III, Toledo 1989, pp. 11-24.

${ }^{83}$ Ramón GonZÁLVEZ RUIZ, «La persistencia del rito hispánico o mozárabe en Toledo después del año 1080», Anales Toledanos, 27 (1990) 24. El profesor De las Cagigas lo expresa con un párrafo elocuente: «Y aquí nos espera una nueva sorpresa. Alfonso, que había abolido el rito antiguo en sus Esta-
} 


\section{CONCLUSIÓN}

El contexto renacentista y la restauración de la liturgia hispánica promovida por Cisneros en Toledo despertaron en la historiografía local un especial interés por difundir su venerable antigüedad y sus vicisitudes históricas. En esta mirada retrospectiva, los intelectuales eclesiásticos y humanistas de la ciudad imperial tratan de llenar una laguna historiográfica significativa, a saber, la razón por la cual el rito de los mozárabes había pervivido tras la decisión de sustituirlo por el romano. Hemos podido distinguir tres tipos diferentes de argumentación. Sin duda, la más original es la legendaria de Blas Ortiz, Juan de Mariana y Francisco de Pisa, construida a partir del relato de la ordalía del fuego, manipulado con la finalidad de que los dos ritos puedan ser considerados dignos de una aprobación divina y una legítima sanción real. De este modo, uno de los elementos más débiles de la cronística medieval se convierte en el elemento clave de esta interpretación. La segunda, que hemos denominado «retributiva» y que tiene un cierto matiz concesivo, se basa en los méritos de una comunidad mozárabe fiel durante siglos a la fe católica y a los usos litúrgicos primitivos en las seis parroquias toledanas. Por último Gómez de Castro, lejos de recurrir a lo épico, propone una interpretación bastante realista como solución pacífica del conflicto ritual. Podemos afirmar que en todas ellas, especialmente en la legendaria, más allá de una reconstrucción de la realidad histórica, existe una voluntad de legitimar la pervivencia de una liturgia viva cuando la implantación de un rito extraño amenazaba su existencia.

\footnotetext{
dos de allende los puertos, lo conserva y ampara -después de algunas vacilaciones- en su nueva conquista, para atraerse a los muchos pobladores mozárabes que le miraban con recelo»; Isidro DE LAS CAGIGAS, Minorías étnico-religiosas de la Edad Media española I: Los mozárabes, t. II, Madrid 1948, p. 466.

Hispania Sacra, LIX

119, enero-junio 2007, 141-162, ISSN: 0018-215-X
} 